\title{
An exploration of occupation in nursing home residents with dementia
}

\author{
Mark Morgan-Brown, ${ }^{1}$ Marcus Ormerod, ${ }^{2}$ Rita Newton ${ }^{3}$ and Dympna Manley ${ }^{4}$
}

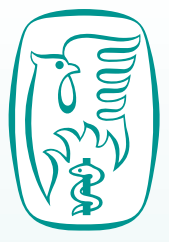

Key words:

Dementia, nursing home, observation, occupation, social engagement.

\footnotetext{
${ }^{1}$ Senior Occupational Therapist, Assessment and Rehabilitation Unit for the Elderly, Cavan General Hospital, Cavan, County Cavan, Ireland.

2 Professor, SURFACE Inclusive Design Research Centre, University of Salford, Salford.

${ }^{3}$ Course Leader, SURFACE Inclusive Design Research Centre, University of Salford, Salford.

${ }^{4}$ Senior Occupational Therapist, Occupational Therapy Department, Monaghan General Hospital, Monaghan, County Monaghan, Ireland.
}

Corresponding author: Mark Morgan-Brown, Senior Occupational Therapist, Assessment and Rehabilitation Unit for the Elderly,

Cavan General Hospital, Cavan,

County Cavan, Ireland.

Email: mark.brown@hse.ie

Reference: Morgan-Brown M, Ormerod M, Newton R, Manley D (2011) An exploration of occupation in nursing home residents with dementia. British Journal of Occupational Therapy, 74(5), 217-225.

DOI: 10.4276/030802211X13046730116452

(C) The College of Occupational Therapists Ltd. Submitted: 26 January 2010.

Accepted: 6 March 2011.
Objectives: This study evaluated the sitting room environment of two nursing homes in Ireland, using interactive occupation and social engagement as outcome measures and defining these rooms as occupational spaces.

Method: Snapshot observational recordings were made in the main sitting rooms during the periods of time when the rooms were in most active use. Narrative information was also recorded.

Results: Residents were more likely to occupy their time in the main sitting room passively, rather than in interactive occupation and social engagement. The nursing home residents with dementia spent approximately $70 \%$ of their daily time in the main sitting room areas in states of occupational disengagement.

Discussion: Additional insight is provided through pragmatic narrative descriptions of the functioning of the main sitting room environment in terms of interactive occupation and social engagement.

Relevance: The research study demonstrates a methodology for evaluating the sitting room areas of a care environment, using interactive occupation and social engagement as outcome measures, which can be used for descriptive and comparative insights into the performance of care environments.

\section{Introduction}

In Ireland, the cost of dementia care in 2006 was estimated to be $€ 400$ million, or $0.7 \%$ of its gross national product. One-third of this was spent on residential care, $25 \%$ of which was paid for by direct public funding (O'Shea 2007).

The prevalence of dementia is linked to increasing age and the number of the oldest old is rising, with considerable potential increases in the costs of dementia care in the next decades. It will be a major driver of costs in health care in developed countries (Wimo et al 2006), with fears about the ability of society to cope with these costs (Wimo et al 1997). Since the care of people with dementia in nursing homes is expensive, it is important for it to be evaluated and studied (Winblad et al 1999) in order to establish standards of care and value for money.

Although various opinions are expressed concerning crucial design features, such as household kitchens, discrete household entrances and open plan communal rooms, these design components are not well served by empirical scientific investigation (Gitlin et al 2003, O'Malley and Croucher 2005, Calkins 2009). There is now growing research interest in evaluating the living experience of people with dementia in nursing homes (Zimmerman et al 2005, Slaughter et al 2006). However, it is complex and challenging to evaluate staff, visitor and resident interactions within residential care environments (Gilster et al 2002).

\section{Aims and definitions}

The aim of this research was to develop and report on a method of measuring the time use of residents with dementia in a nursing home. In order to 
create a useful distinction between the different ways that residents used time, the term 'interactive occupation' is employed in this study. It is defined as being an active observable behavioural interaction with the environment or with a task. Interactive occupation is distinguished from other categories of behavioural occupation, such as self-stimulation, agitation and non-engagement, and from receiving and being directed in personal care. It is further distinguished from social engagement, which is defined as a behaviourally observable verbal or non-verbal interaction with another person(s).

Two categories captured passive behaviours: (a) nonengagement, which is having one's eyes open but without any observed interaction with the environment or a person, and (b) eyes closed. This research did not attempt to distinguish if the person with eyes closed was asleep or not. In either case, this behaviour indicates exclusion from, and non-interaction with, the external environment.

\section{Literature review}

\section{Positive effects of occupation and social engagement}

Being active is a powerful human drive and its absence constitutes a significant threat to wellbeing (Perrin 2000). It is through 'doing' and participating that people with dementia find meaning in their lives: through a sense of pleasure and enjoyment, and a sense of connection and belonging, as well as by retaining a sense of autonomy and personal identity (Phinney et al 2007). Occupation and social engagement have a positive effect on people with dementia in nursing homes (Morgan and Stewart 1997, Marshall and Hutchinson 2001). However, not all occupational and social interventions are universally effective. Research outcomes are variable and success depends on being able to engage the abilities and interests of participants (Voelkl et al 1995, Kolanowski et al 2005, Cohen-Mansfield et al 2010). However, Litwin and Shiovitz-Ezra (2006) argued that social engagement, rather than activity participation, predicts wellbeing in older people.

\section{Observational studies: residents with dementia in care environments}

There are different methods of obtaining daily life observational data of people with dementia living in residential care. The extensive Yorkshire study of Bowie and Mountain (1993) evaluated seven long-stay wards, enabling the observation of 110 residents with dementia over 114 hours. Recording each person in succession for 5 minutes on hand-held organisers, they concluded that two-thirds of a resident's day was spent doing nothing.

In contrast, the Norwegian study of Holthe et al (2007) used an ethnographic approach to evaluate life in a specially designed unit. Eight residents were observed for 45 hours over 8 weeks. Interviews were used to deepen the understanding of the observed behaviour. The residents identified the importance of activities for their own mental and physical health. Despite this, the observational data demonstrated that these residents remained dependent on staff interventions to engage in daily occupations.

Schreiner et al (2005) evaluated the behaviour and affect of 35 residents at two special care units in Japan. Data on observed behaviour, as well as on emotional expression, were collected over 64 hours, with residents being observed for 5 minutes every hour and recorded on their observational form. They concluded that residents spent most of their time alone, doing nothing and with little social interaction. However, they also recorded that when residents were involved in recreational activity, they showed increased levels of positive affect.

Wood et al (2005) used a 10-minute interval recording procedure, employing a computer-assisted hand-held observational tool to measure resident behaviour, affect and activity situations in the United States. They found residents to be disengaged, inactive and without positive emotional expression. They concluded that having a home-like physical environment was insufficient to create engagement and they recommended further investigation as to how environments can be transformed into places of occupation, which they described as 'alive occupational spaces'. Using the same procedure, Wood et al (2009) collected data from two special care units for people with Alzheimer's disease. Observations were made of 14 residents across four 12 -hour days. They found a paucity of staff-resident interactions and a lack of resident engagement with their environment. They recommended the involvement of occupational therapists as educators, mentors and consultants to enhance the effectiveness of routine activity situations and everyday occupations.

\section{Method}

\section{Setting}

This study was conducted in the dementia-specific unit of two large private nursing homes ( $\mathrm{NH}$ and $\mathrm{NH} 2$ ) in Ireland by the first author. All authors were independent of any financial or other connection to the nursing homes. Both nursing homes intended to commence major renovations to provide a more 'home-like' or 'household' model of care.

The nursing homes had dining rooms separate from the sitting rooms, requiring staff to orchestrate the movement of residents from one room to the other at mealtimes. It was intended that each household renovation would provide an inclusive communal kitchen in the main sitting room area, allowing food and beverages to be provided directly from the kitchen into the open plan living and dining area and eliminating the institutional movement of residents from one room to the other. The kitchen would facilitate familiar domestic tasks and social connection patterns around kitchen tables in the open plan communal living environment. Each household would have its own separate front door, defining it as distinct from the rest of the nursing home complex. This study provides a baseline assessment against which the newly renovated household environments could be measured. 
Table 1. Nursing home 1: description of the residents

\begin{tabular}{|c|c|}
\hline Number of reside & 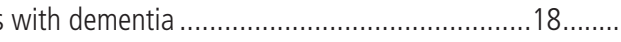 \\
\hline MMSE scores (rar & . \\
\hline MMSE scores (me & $\ldots 8.6 \ldots$ \\
\hline$\%$ dependent: & Meals....... \\
\hline & Dressing.......... \\
\hline & Hygiene..... \\
\hline & Micturition ............... \\
\hline & Defecation \\
\hline \% impairments: & Vision............. \\
\hline & Hearing ............................. \\
\hline & 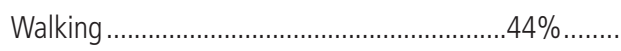 \\
\hline & Talking ........................... \\
\hline Diagnosis & 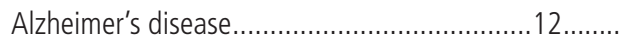 \\
\hline & Vascular dementia \\
\hline & Dementia.................. \\
\hline & Non-diagnosed \\
\hline & Trauma \\
\hline & Multi-infarct .. \\
\hline & Lewy body....... \\
\hline
\end{tabular}

MMSE = Mini Mental State Examination.

\section{Background}

The staffing levels for both nursing homes were one nurse and two care workers on duty during each morning and evening observation period, and two care workers on duty during each afternoon observation period. In addition, both homes employed a part-time activity coordinator.

The cognitive status of the residents was measured by the Mini Mental State Examination (MMSE), as devised by Folstein et al (1975), which has satisfactory reliability and construct validity, with high levels of sensitivity for moderate to severe cognitive impairment (Tombaugh and McIntyre 1992). The MMSE assessment procedure was known to the nursing staff of each nursing home. All demographic information was provided by the nursing staff of each unit and was recorded within the 4 weeks preceding the research observations. Names were not given and individuals were not identified.

There were 18 residents with dementia in the NH1 unit, who were all included in this study whenever they entered the sitting room. Of the 22 residents in $\mathrm{NH} 2$, five were people who had an acquired brain injury. From time to time, these individuals came in, or were brought into, the main sitting room and were, therefore, included in the observational count of all residents who spent any time in the sitting room. In practice, their behaviour was indistinguishable from that of other residents in terms of occupation and social engagement within the room environment. Their demographic information has not been included in NH2 (Table 2).

\section{Principles of focus}

Van Haitsma et al (1997) had specific recommendations for observational studies, based on their extensive research experience. They recommended targeting:
Table 2. Nursing home 2: description of the residents

\begin{tabular}{|c|c|}
\hline Number of reside & s with dementia. \\
\hline MMSE scores (rar & $\ldots 12-0 \ldots \ldots \ldots$ \\
\hline MMSE scores (me & ....6.4.. \\
\hline$\%$ dependent: & Meals.. \\
\hline & Dressing......................... \\
\hline & $\ldots 100 \% \ldots \ldots . .$. \\
\hline & Micturition..... \\
\hline & Defecation ....................... \\
\hline \% impairments: & $\ldots \ldots \ldots \ldots . . .18 \% \ldots \ldots$ \\
\hline & 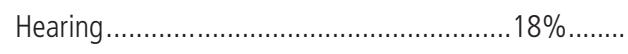 \\
\hline & 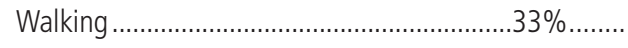 \\
\hline & Talking ............................ \\
\hline Diagnosis & Alzheimer's disease \\
\hline & 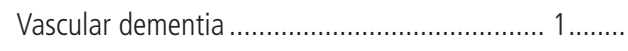 \\
\hline & Dementia................ \\
\hline & 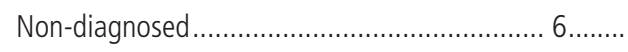 \\
\hline & Trauma \\
\hline & 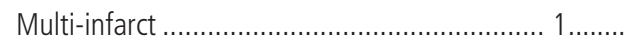 \\
\hline & 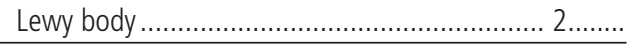 \\
\hline
\end{tabular}

MMSE = Mini Mental State Examination.

(a) Time of day and activity times

(b) Specific locations

(c) Certain behaviours

This research was devised to comply with these recommendations by:

(a) Recording only the behaviours in the 2-hour slot between meals (morning and afternoon sessions), and between the last meal and bedtime (evening sessions)

(b) Excluding environments defined by care activity (bedrooms, bathrooms, toilets) and, instead, focusing on the communal living rooms

(c) Concentrating on observable occupation and social engagement behaviours as outcome measures.

\section{Procedure}

In order to achieve a valid representation of the activity in the sitting rooms, two criteria had to be fulfilled. The intervals of observation needed to be consistent and the observations needed to be as frequent as possible, in order to capture as much information as possible and to reduce error (Perrin 1997a). A trial was undertaken in a day hospital waiting room to determine how quickly an observer could categorise the occupations and social interactions of up to 20 people within a room, with a suitable time remaining to prepare for the next recording incident. Through trial and error, this was determined to be 5 minutes in duration.

Each nursing home observation session lasted for 2 hours. Half the observations for each nursing home were during both morning and afternoon (10:00-12:00 and 14:00 to 16:00), with the alternating observations taken during both afternoon and evening (14:00-16:00 and 18:00-20:00). This scheduling avoided times when the sitting room would be deserted because the residents would be elsewhere (dining room for meals, bedrooms for getting up and going to bed). 
During an observation session, a seat was selected from which to observe everyone in the room. The observer consistently chose the same position in order to be as unobtrusive as possible. At 5-minute intervals, a recording was made on the observation sheet of each person in the room, which categorised his or her occupation and social engagement. Brief narrative information was recorded to support retrospective interpretation of the data. Line drawings and brief narrative comments were recorded on the backs of the assessment sheets, indicating the relative positioning and functioning of any person in the room for that relevant time.

$\mathrm{NH} 1$ was observed for four different days over 2 weeks (total: 16 hours). NH2 was observed for seven different days over 6 weeks (total: 28 hours). The recording for NH1 had to be reduced due to the early commencement of the construction work. The observations were scheduled for the convenience of the observer and each nursing home, with no two days observed sequentially.

The first author (MMB) undertook all observations for both homes. Interrater reliability was provided by another of the authors (DM) independently recording one 2-hour session in both nursing homes. The interrater agreement coefficient (total number of times both raters agreed divided by the total judgements made) of the two independent observations was $91.1 \%$ for $\mathrm{NH} 1$ and $98.2 \%$ for $\mathrm{NH} 2$.

\section{Observational protocol: divergence from other studies}

This assessment tool was influenced by other observation tools used to evaluate residents with dementia in nursing homes (Bowie and Mountain 1993, Norbergh et al 2001).

Shields and Norton (2006) argued strongly that bedroom and hallway spaces in a household are private spaces and not open to strangers, and that this should remain true for household residential care environments. This research conformed to this ethical positioning. The observer did not enter private bedroom or hallway spaces to make observations.

This research did not attribute emotional states (happy, sad, anxious, angry) or attribute a state of wellbeing or ill-being to residents with dementia.

\section{Methodological refinement: assessment tool}

An experienced occupational therapist (DM) assisted the prime researcher (MMB) in a pilot study spanning 3 months, in order to define and refine all of the domains of the Assessment Tool for Occupation and Social Engagement (ATOSE) until there was a high level of interrater reliability (over 90\% agreement). A written protocol was devised to enable future consistency in observation procedure and behaviour categorisation. The ATOSE categories for residents were (1) interactive occupation, (2) social engagement, (3) non-engagement, (4) eyes closed, (5) receiving care and (6) agitation and self-stimulation.

\section{Methodological issues: ethics}

This research used the guidelines of process consent (Dewing 2002, Cantley et al 2005) to obtain consent from the residents in their own right, rather than proxy consent from relatives. Residents were introduced to the observer and the purpose of the research individually, with the detail tailored to the cognitive capacity of each resident. Greetings were given to the residents whenever the observer entered or left the room. The observer was prepared to stop the research process at any sign of discomfort or disagreement. This happened once only and the resident became comfortable when shown that no names were recorded, allowing the observation to continue.

The research protocol received ethical consent from the University of Salford, in the United Kingdom, and by the Healthcare Research Advisory Committee of the Dublin North East Region Health Authority, in Ireland.

\section{Results}

A description of the residents of each unit is given in Tables 1 and 2 . The cognitive status, as measured by the MMSE scores, was lower in NH2, indicating a more severe cognitive impairment.

For the observations, there was an average of nine residents to code for each 5-minute segment for $\mathrm{NH} 1$. NH2 had a much larger sitting room containing many more chairs, with more residents typically making use of the room (average 12 per 5 -minute segment). At each observation, each resident was given a marker indicating the categories to which their behaviour fitted most closely at that snapshot moment in time. Tables 3 and 4 give the total results of the numbers of markers (indicating the number of times residents were observed in each category over the evaluation period). The total resident markers for interactive occupation and social engagement were approximately $28 \%$ for $\mathrm{NH} 1$ and $20 \%$ for $\mathrm{NH} 2$.

If the interactive occupation and social engagement categories were combined together for NH1, the percentage of time spent in 'interactive engagement' ranged from $16.96 \%$ to $37.23 \%$ (average of the four days, $27.66 \%$ ). For $\mathrm{NH} 2$, the daily combined 'interactive engagement' category percentages ranged from $11.36 \%$ to $27.23 \%$ (average of the seven days, 19.84\%). The markers for the resident behaviours in the combined passive non-engaged, selfstimulatory, agitated and receiving care categories were approximately $72.34 \%$ for $\mathrm{NH1}$ and $80.16 \%$ for $\mathrm{NH} 2$. As the staff and visitor presence observed in each sitting room was nearly equivalent, there are two likely explanations for the differences found in interactive occupation and social engagement values. The lower levels of interactive occupation and social engagement in $\mathrm{NH} 2$, compared with $\mathrm{NH} 1$, are associated with a greater level of cognitive impairment, as given by the MMSE scores, and a greater level of dependence. Because of the more intimate size of the sitting room in $\mathrm{NH1}$, there were greater opportunities for informal and spontaneous interactions. NH2 had a much larger sitting room, with residents' chairs around the walls. 
Table 3. Nursing home 1: total markers across four days

\begin{tabular}{|c|c|c|}
\hline & No. of markers & $\%$ of total \\
\hline 1. Interactive occupation.................. & $\ldots .252$. & $\ldots .17 .73 \% \ldots$ \\
\hline 2. Social engagement... & $\ldots 141 \ldots$ & $\ldots . .9 .93 \% \ldots$ \\
\hline 3. Non-engaged... & $\ldots . .546 \ldots \ldots$ & $\ldots .38 .42 \% \ldots$ \\
\hline 4. Eyes closed..... & $\ldots . .436 \ldots .$. & $\ldots 30.68 \% \ldots$ \\
\hline 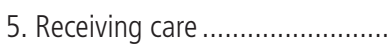 & ........20....... & ......1.41\% .... \\
\hline 6. Agitation and self-stimulation.. & $\ldots .26 \ldots$ & ......1.83\% $\ldots$. \\
\hline Total markers & $\ldots \ldots . .1421 \ldots \ldots$. & $\ldots . .100 \% \ldots$ \\
\hline Categories $1+2 \ldots \ldots \ldots \ldots \ldots \ldots$ & $\ldots \ldots \ldots . . .393 \ldots . .$. & $\ldots .27 .66 \% \ldots$ \\
\hline Categories $3+4+5+6 \ldots \ldots \ldots \ldots$ & $\ldots \ldots \ldots .1028 \ldots \ldots \ldots$ & $\ldots .72 .34 \% \ldots$ \\
\hline
\end{tabular}

The interventions of the activity coordinators in each home usually focused on one or two persons at a time, rather than universally within the room, as few residents were able to sustain interest in an activity on their own. As the work was mostly one-to-one at any snapshot moment in time, and as most of the room occupants were unoccupied until they were directly engaged by the coordinator, the total daily markers of resident occupation and social engagement did not increase substantively.

Observational methods provide a rich and accurate source of data (Bowie and Mountain 1993). However, while interval recording provides quantitative information, it does not give context and understanding of the observed phenomena and must be supplemented by narrative description. This narrative information is given below.

\section{Physical environment}

Both traditional nursing home sitting rooms discouraged interactive occupation and social engagement. Residents sat parallel around the edges of the room. (It is uncomfortable for any person, with or without dementia, to sit in the middle of a room, with a circle of people in chairs gazing in from around the periphery.) Staff and visitors rarely moved chairs away from this configuration, even when this would facilitate their own communication. Staff stood and talked to residents or sat parallel with them. There were no tables in the room to allow people to talk over a cup of tea or to engage in a facing position. The rooms did not provide smaller individual areas to sit, which would create a sense of place, location and destination for residents and their visitors, encouraging formal and informal encounters with others. The stimulus-poor physical environment was lacking in things for residents to pick up and do, or for staff and visitors to pick up and do with the residents.

\section{Tea trolley ritual}

In sharp contrast to the uneventful use of the room, the provision of tea and food engaged everyone on some level within the room and enlivened the room. No other occupation approached this level of engagement. However, this activity was treated as yet another care task, with residents and visitors passively, rather than actively, involved in the creation, organisation and distribution of the tea and food. The potential opportunities for interactive occupation and
Table 4. Nursing home 2: total markers across seven days

\begin{tabular}{|c|c|c|}
\hline & No. of markers & $\%$ of total \\
\hline 1. Interactive occupation................ & $\ldots . .573 \ldots$ & $\ldots 15.88 \% \ldots$ \\
\hline 2. Social engagement.. & $\ldots 143 \ldots$ & $\ldots . .3 .96 \% \ldots$ \\
\hline 3. Non-engaged ............ & $\ldots 1724 \ldots \ldots$ & $\ldots .47 .77 \% \ldots$ \\
\hline 4. Eyes closed..... & $\ldots .776 \ldots$ & $\ldots 21.50 \% \ldots$ \\
\hline 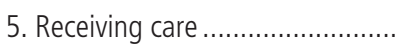 & $\ldots \ldots .85 \ldots \ldots$ & $\ldots . . .2 .36 \% \ldots$ \\
\hline 6. Agitation and self-stimulation ... & ...308.. & $\ldots . .8 .53 \% \ldots$ \\
\hline Total markers.... &.. $.3609 \ldots \ldots$ & $\ldots \ldots 100 \% \ldots$ \\
\hline Categories $1+2 \ldots \ldots \ldots \ldots \ldots \ldots \ldots$ & $\ldots \ldots . .716 \ldots . .$. & $\ldots .19 .84 \% \ldots$ \\
\hline Categories $3+4+5+6 \ldots \ldots \ldots$ & $\ldots .2893 \ldots \ldots$ & $\ldots 80.16 \% \ldots$ \\
\hline
\end{tabular}

social engagement of residents, staff and visitors were lost. As all residents were served by staff from the trolley, the activity reinforced dependency and passivity. Each resident drank his or her tea in silence and in an attitude of isolation, sitting alongside others with their chairs arranged around the walls.

Even when action was happening in the room - for example, the tea trolley being prepared - most residents did not make visual contact until a staff member brought the tea to them. Having the tea did not improve eye contact or social interaction between residents because they continued to sit parallel around the periphery, facing into the centre of the room.

\section{Use of television and DVDs}

The television was almost always on in both nursing homes. The residents sat around the walls of the room with the television prominently placed as the main focal point. Except as detailed below, the residents rarely looked at the television screen. Inappropriate television programmes frequently came on for the residents (including those depicting people with agitation, anxiety and anger, or commentators talking incessantly about complicated topics such as the economy). However, the television was still left on for most of the day in both homes. A radio was sometimes on at the same time. The residents had no control over these sounds, which permeated the room. There were no areas in the sitting room where residents could go if they did not wish to be exposed to these sounds. This research supports the conclusion of Wood et al (2009), which associates the ongoing use of television with poor quality of life indicators. They depict the use of television as being overwhelming and immobilising for residents with dementia.

There were very rare occasions when a small number of residents were observed to pay attention to the television for limited units of time. Their attention was briefly engaged by specific DVDs with familiar songs, or children singing (such as The Sound of Music). This happened primarily in $\mathrm{NH1}$, where the sitting room was smaller, allowing a more immediate connection to the television by a group of women who tended to sit together on a sofa, creating an informal group dynamic. In the much more open and larger spaces of NH2, there were no instances of visual engagement. However, on one day, a reminiscence DVD of 
old farming procedures was of intense interest to one blind male resident, who engaged the $\mathrm{NH} 2$ activity coordinator in discussion about it for an extended time.

\section{Staff interaction}

The residents were unoccupied when staff were not in the room. Perrin (1997b) and Holthe et al (2007) also identified that residents with dementia are dependent upon staff to initiate occupation and social engagement.

It is uncomfortable for anyone to remain in the centre of a circle of people sitting around the edges of a room unless there is a specific task to be done. When staff were in the room without a care task, they appeared uncomfortable, as if they did not know what to do, and they searched for a care task to undertake. During the observation sessions, it was rare for any staff member to engage in social conversation or occupation, unless the purpose of the engagement was the accomplishment of a care task, such as transferring or mobilising.

There was a lack of suitable activity resources available to staff, and the few that there were (puzzles, pictures, books) appeared to be the sole province of the activity coordinator. Both nursing homes employed a widely used, commercially available, structured exercise and sensory stimulation programme on a weekly basis. The residents, sitting around the walls, did not engage with the taped instructions and only responded when the coordinator made direct facing contact with them. This meant that only a few residents were engaged with the activity at one time. It was observed that no men participated in these programmes.

\section{Relative interactions}

In both nursing homes, there was a general lack of visitors and the visits were often less than 15 minutes in duration. The environment was stimulus-poor: there were no environmental prompts, such as joint activities, tasks or routines, to share with the residents, so the burden of engagement was left to conversation. The lack of intimate groupings of soft furnishings or casual kitchen-table seating made conversation more difficult. Relatives rarely moved the seating from its position around the walls into a facing position, so conversation was in the awkward parallel sitting position with little sense of privacy and intimacy. Most relatives resolved this dilemma by taking the resident out of the main living area and into his or her bedroom. This solution compromised the resident's right to privacy, with relatives entering a private bedroom space and often sitting on the person's bed.

\section{Discussion}

\section{Observational study context}

Caution must be applied when comparing this study to other observational studies. People with dementia spend their time in residential care because of the following: the inclusion of different groups of residents with different functional and cognitive abilities; different care environments ranging from small group homes (Wood et al 2009) to seven hospital psychogeriatric wards (Bowie and Mountain 1993); and different methods of assessment and categorisations of observed behaviour.

Mealtimes and tea breaks produce a flurry of activity and physical interaction, if not social engagement. This study includes the routine provision of tea to the residents during all sessions at both homes. This is not reported or examined in any of the research studies listed below, although most include mealtimes, which this study does not.

This study found high levels of non-active behaviour: the percentage of time that residents spent in non-engaged and eyes closed categories was $69.1 \%$ for $\mathrm{NH} 1$ and $69.3 \%$ for $\mathrm{NH} 2$. These figures are in the upper range of other observational studies (56.5\% for Bowie and Mountain 1993; 41\% for Norbergh et al 2001; 51\% for Smallwood et al 2001; 48.9\% for Schreiner et al 2005; and 72\% for Wood et al 2009).

Nolan et al (1995) observed patients on two psychogeriatric wards, where passive behaviours for long-stay residents were $77 \%$. For respite patients, passive behaviours constituted $31 \%$ of time spent, and for short-stay residents they were $40 \%$ of time spent. The authors conjectured that because the respite and short-stay patients were more active and more socially engaging, this, in turn, attracted even more interaction from other patients and from staff.

Bowie and Mountain (1993) expressed concern at the 'worryingly low' level of social engagement that they found in daily time use (5.5\%). In the present study, social engagement constituted $9.9 \%$ of resident time use in $\mathrm{NH1}$ and $4.0 \%$ of time use in NH2. Two other studies have reported social engagement values: $17.9 \%$ for Schreiner et al (2005) and 12.4\% for Wood et al (2009).

Agitated and self-stimulatory behaviour is recorded in several studies. This study observed self-stimulating and agitated behaviours of less than $2 \%$ for $\mathrm{NH1}$ and $8.5 \%$ for $\mathrm{NH} 2$. Schreiner et al (2005) reported agitated behaviours as being below $1 \%$ of all observations. If their wandering (1.3\%) and meaningless behaviour (3.2\%) categories are comparable to this study's self-stimulating category, their comparable total is $5.5 \%$, roughly midway between the two nursing home scores in this study. Like this study, they excluded the morning and bedtimes, with concomitant personal care, where agitated behaviours are more likely to occur. In contrast, Bowie and Mountain (1993) included observations of personal care during the morning, bedtimes and mealtimes of seven psychiatric wards for patients with dementia, who were found to spend $30.2 \%$ of their time in motor activity (aimless, restless or repetitive), antisocial behaviours and inappropriate behaviours. The authors commented on the staff's preoccupation with physical care and their lack of social engagement with the patients in these ward environments.

Smallwood et al (2001) used the Bowie and Mountain (1993) categories. However, they did not observe getting up, going to bed and mealtime behaviours. They recorded results of $28 \%$ of time spent in motor, antisocial and inappropriate behaviours, which is similar to the earlier Bowie and Mountain (1993) results as above. Both of these results 
contrast sharply with the low figures in this study's results, suggesting that further exploration would be valuable in developing an understanding of how physical and social environments affect patients/residents with dementia.

Most observational research studies use a limited number of categories in parallel to this study. Bowie's and Mountain's (1993) categorisations are most similar to those used in this study: self-care, social engagement, reception of care, motor activity (wandering, restless, fidgeting), antisocial, inappropriate and neutral behaviours (detached, doing nothing, sleeping). However, like most of the above studies, they used a 'stream of behaviour' methodology, sequentially recording everything that happened to each individual over a set period and then moving on to observe another person, thereby building up a composite picture of a whole room environment. In contrast, this study reports on whole room activity in a snapshot of time.

Counterintuitively, Wood et al (2009) found that residents in the more traditional nursing home demonstrated a more engaged gaze and were more likely to show pleasure than in the more home-like nursing home they investigated. They attributed this differential to the larger, more traditional unit having a busier environment, where 'many more of its residents and staff milled around, occasionally interacting, and more events and activities naturally occurred' (p344). They concluded that quality of life was not enhanced by the special design features of the smaller home-like facilities.

These reported observational studies demonstrate the complexity and variety of the work with people with dementia in care environments. By refining and consolidating observational study techniques, protocols and outcomes, a clearer picture will emerge concerning the effect of the built and social environments on quality of life for people within those environments.

There are implications and opportunities for occupational therapists working in these environments. This study demonstrates that one-to-one engagement with residents contributes only a small proportion of whole room interactive occupation and social engagement levels. The challenge for occupational therapists is how to use the whole room environment, with its physical and social components, to orchestrate opportunities for a wider social and occupational engagement in order to maximise spontaneous interactions.

There is potential to improve life for residents with dementia living in care environments. Critical day-to-day events having to do with food and beverage are opportunities for interactive occupation and social engagement, potentially involving everyone in the room. There is an expectation that creating a household environment will provide additional opportunities for familiar, over-learned, and repetitive tasks, which are retained in the repertoire of the residents and can nurture and provide a sense of comfort. It is anticipated that performing these household tasks in a home-like environment will be self-rewarding and self-motivating for at least some residents, providing continuity with previous occupational roles and identity.
Whiteford (2000) challenged the profession to 'think and act at a broader social and cultural level' (p203), rather than focusing exclusively on therapeutic interventions with individuals. Occupational therapists are able to contribute in a unique way to the understanding of how the environment influences the people and culture within it, the activities they perform and the social engagements that they make (Green and Cooper 2000, Robertson and Fitzgerald 2010). Occupational therapists are aware that the environment has an impact on social and occupational engagement, as well as wellbeing, and they frequently use this in their interventions. Currently, there is little evidence of how the specific components of an environment, such as the use of television, the positioning of chairs within a room or the installation of a communal kitchen, will affect interactive occupation and social engagement. Further investigation is required to construct this evidence.

\section{Limitations of the study}

Sitting quietly in a corner as an observer provides a unique opportunity to understand what is happening in an environment. Undoubtedly, the presence of the observer had an effect on the people within the room. The staff noted in NH1 that the presence of the observer attracted residents to enter and stay in the main sitting room. Conversely, the presence of the observer could have discouraged visitors and staff from staying in the room. However, on balance, work and life appeared to go on normally, without undue attention being directed towards the observer.

The focus of this research was purposely restricted to the sitting room environments, so it did not take into account the total work that staff provided in resident bedrooms, toilets or showers; nor did it include the occupations of the residents and their visitors in other areas.

Woods (1999) argued that wellbeing may reflect a state of having no or few unmet needs, rather than a transitory emotional state. The present study did not seek to determine the emotional state of residents. The strategic standpoint that this study took was that interactive occupation and social engagement were human needs and were, therefore, legitimate outcome measures. Interactive occupation and social engagement did not require breakdown into emotional states, or other signs of wellbeing, for justification.

\section{Conclusion}

This study reports a poor level of interactive occupation and social engagement of residents with dementia living in two traditional nursing homes. It describes an observational procedure for evaluating these outcomes within a room environment. Narrative descriptions are given, which describe the impact of the physical and cultural environment on those present within it.

This research identifies that some people with dementia in residential care spend a small proportion of their day in interactive and engaged behaviours, and that residential care 
environments can be evaluated by occupational therapists as 'occupational spaces' (Hasselkus 1998, Wood et al 2005). This knowledge can be used to distinguish and compare environments, enabling better care environments and a consequent improvement in quality of life for people with dementia.

The ATOSE is a tool that enables the quantitative measurement of interactive occupation and social engagement behaviours in a room environment. The measurement enables a comparative evaluation of care environments, emphasising the outcome measures of interactive occupation and social engagement.

This procedure may be useful for many occupational therapists because it gives an appraisal process upon which to research, quantify and compare the impact of specific interventions on residential care environments.

\section{Acknowledgements}

The authors would like to acknowledge both the time and the assistance given by the management of both nursing homes to set up this research study. They would also like to acknowledge the residents who cooperated with the study, as well as the cooperation of visitors and staff present during the observation sessions. The authors gratefully acknowledge the time, attention and insight of the anonymous BJOT peer reviewers in the formation of this journal article. The first author thanks the Health Service Executive for partial funding of his $\mathrm{PhD}$ research.

Conflict of interest: None declared.

\section{Key findings}

- Occupation and social engagement levels were poor for people with dementia for two traditional nursing home environments.

- Routines involving food and drink are critical occupational and social engagement opportunities.

- Environmental influences on occupation and social engagement in nursing home environments can be detected.

\section{What the study has added}

This study demonstrates an assessment procedure that provides quantitative and qualitative analysis of a residential care environment in terms of occupation, social engagement and non-engaging behaviours.

\section{References}

Bowie P, Mountain G (1993) Using direct observation to record the behaviour of long-stay patients with dementia. International Journal of Geriatric Psychiatry, 8(10), 857-64.

Calkins MP (2009) Evidence-based long term care design. NeuroRehabilitation, 25(3), 145-54.

Cantley C, Woodhouse J, Smith M (2005) Listen to us: involving people with dementia in planning and developing services. Newcastle upon Tyne: Dementia North and Northumbria University.

Cohen-Mansfield J, Marx MS, Thein K, Dakheel-Ai M (2010) The impact of past and present preferences on stimulus engagement in nursing home residents with dementia. Aging and Mental Health, 14(10), 67-73.

Dewing J (2002) From ritual to relationship: a person-centred approach to consent in qualitative research with older people who have dementia. Dementia, 1(2), 157-71.
Folstein MF, Folstein SE, McHugh PR (1975) 'Mini-mental-state'. A practical method for grading the cognitive state of patients for the clinician. Journal of Psychiatric Research, 12(3), 189-98.

Gilster SD, Accorinti KL, Dalessandro JL (2002) Providing a continuum of care for persons with Alzheimer's disease. Alzheimer's Care Quarterly, 3(2), 103-15.

Gitlin LN, Liebman J, Winter L (2003) Are environmental interventions effective in the management of Alzheimer's disease and related disorders? A synthesis of the evidence. Alzheimer's Care Quarterly, 4(2), 85-107.

Green S, Cooper BA (2000) Occupation as a quality of life constituent: a nursing home perspective. British Journal of Occupational Therapy, 63(1), 17-24.

Hasselkus BR (1998) Occupation and well-being in dementia: the experience of day-staff. American Journal of Occupational Therapy, 52(6), 423-34.

Holthe T, Thorsen K, Josephsson S (2007) Occupational patterns of people with dementia in residential care: an ethnographic study. Scandinavian Journal of Occupational Therapy, 14(2), 96-107.

Kolanowski AM, Litaker M, Buettner L (2005) Efficacy of theory-based activities for behavioral symptoms of dementia. Nursing Research, 54(4), 219-28.

Litwin H, Shiovitz-Ezra S (2006) The association between activity and wellbeing in later life: what really matters? Ageing and Society, 26(2), 225-42.

Marshall MJ, Hutchinson SA (2001) A critique of research on the use of activities with persons with Alzheimer's disease: a systematic literature review. Journal of Advanced Nursing, 35(4), 488-96.

Morgan DG, Stewart NJ (1997) The importance of the social environment in dementia care. Western Journal of Nursing Research, 19(6), 740-61.

Nolan M, Grant G, Nolan J (1995) Busy doing nothing: activity and interaction levels amongst differing populations of elderly patients. Journal of Advanced Nursing, 22(3), 528-38.

Norbergh KG, Asplund K, Rassmussen BH, Nordahl G, Sandman PO (2001) How patients with dementia spend their time in a psycho-geriatric unit. Scandinavian Journal of Caring Sciences, 15(3), 215-21.

O'Malley L, Croucher K (2005) Housing and dementia care - a scoping review of the literature. Health and Social Care in the Community, 13(6), 570-77.

O'Shea E (2007) Implementing policy for dementia care in Ireland: the time for action is now. Dublin: Alzheimer Society of Ireland.

Perrin T (1997a) The positive response schedule for severe dementia. Aging and Mental Health, 1(2), 184-91.

Perrin T (1997b) Occupational need in severe dementia: a descriptive study. Journal of Advanced Nursing, 25(5), 934-41.

Perrin T (2000) Doing and being in dementia: a return journey? Alzheimer's Care Quarterly, 1(2), 29-37.

Phinney A, Chaudhury H, O'Connor DL (2007) Doing as much as I can do: the meaning of activity for people with dementia. Aging and Mental Health, 11(4), 384-93.

Robertson L, Fitzgerald R (2010) The conceptualisation of residential home environments: implications for occupational therapy. British Journal of Occupational Therapy, 73(4), 170-77.

Schreiner AS, Yamamoto E, Shiontani H (2005) Positive affect among nursing home residents with Alzheimer's dementia: the effect of recreational activity. Aging and Mental Health, 9(2), 129-34.

Shields S, Norton L (2006) In pursuit of the sunbeam. USA: Action Pact Press. 
Slaughter S, Calkins M, Eliasziw M, Reimer M (2006) Measuring physical and social environments in nursing homes for people with middle-to late-stage dementia. Journal of the American Geriatrics Society, 54(9), 1436-41.

Smallwood J, Irvine E, Coulter F, Connery H (2001) Psychometric evaluation of a short observational tool for small-scale research projects in dementia. International Journal of Geriatric Psychiatry, 16(3), 288-92.

Tombaugh TN, Mclntyre NJ (1992) The mini-mental state examination: a comprehensive review. Journal of the American Geriatrics Society, 40(9), 922-35.

Van Haitsma K, Lawton MP, Kleban MH, Klapper J, Corn J (1997) Methodological aspects of the study of streams of behavior in elders with dementing illness. Alzheimer Disease and Associated Disorders, 11(4), 228-38.

Voelkl JE, Fries BE, Galecki AT (1995) Predictors of nursing home residents' participation in activity programs. The Gerontologist, 35(1), 44-51.

Whiteford G (2000) Occupational deprivation: global challenge in the new millennium. British Journal of Occupational Therapy, 63(5), 200-04.

Wimo A, Ljunggren G, Winblad B (1997) Costs of dementia and dementia care: a review. International Journal of Geriatric Psychiatry, 12(8), 841-56.
Wimo A, Jonsson L, Winblad B (2006) An estimate of the worldwide prevalence and direct costs of dementia in 2003. Dementia and Geriatric Cognitive Disorders, 21(3), 175-81.

Winblad B, Wimo A, Mobius HJ, Fox JM, Fratiglioni L (1999) Severe dementia: a common condition entailing high costs at individual and societal levels. International Journal of Geriatric Psychiatry, 14(11), 911-14.

Wood W, Harris S, Snider M, Patchel SA (2005) Activity situations on an Alzheimer's disease special care unit and resident environmental interactions, time use, and affect. American Journal of Alzheimer's Disease and Other Dementias, 20(2), 105-18.

Wood W, Womack J, Hooper B (2009) Dying of boredom: an exploratory case study of time use, apparent affect, and routine activity situations on two Alzheimer's special care units. American Journal of Occupational Therapy, 63(3), 337-50.

Woods B (1999) Promoting well-being and independence for people with dementia. International Journal of Geriatric Psychiatry, 14(2), 97-109.

Zimmerman S, Sloane PD, Williams CS, Reed PS, Preisser JS, Eckert JK, Boustani M, Dobbs D (2005) Dementia care and quality of life in assisted living and nursing homes. The Gerontologist, 45(1), 133-46. 